\title{
Fiebre de Chikungunya: Una nueva enfermedad emergente de gran impacto en la salud pública
}

\author{
The Chikungunya Fever: A new emerging disease of great impact in the Public Health
}

Ciro Maguiña-Vargas ${ }^{1, a ; 2, b}$

\section{INTRODUCCIÓN}

Entre los años 1970 al 2010, los investigadores y científicos comenzaron a reportar nuevos agentes infecciosos con sus respectivas dolencias, siendo la mayor parte de ellos de origen viral y bacteriano; por lo que en 1992 el Instituto de Medicina de los Estados Unidos definió un nuevo termino: Las enfermedades emergentes como "aquellas dolencias cuya incidencia se ha incrementado desde las pasadas dos décadas o amenaza incrementarse en un futuro" (1). Al respecto, existen numerosos ejemplos, en 1976 se describe en África una nueva fiebre hemorrágica de alta letalidad, la fiebre hemorrágica del Ébola; en 1981 el Síndrome de Inmunodeficiencia adquirida que causó una gran pandemia; en 1992 la nueva especie Bartonella henselae, es implicada como agente de la angiomatosis bacilar y del arañazo del gato; el 2003 el nuevo virus coronavirus agente del SRAS (2), y el año 2009 el A H1N1 causante de la nueva epidemia del virus Influenza (3).

Paralelamente algunas viejas dolencias como cólera, dengue, tuberculosis (TBC), malaria, entre otras, comienzan a incrementarse a nivel mundial, por ello se le denominan enfermedades reemergentes (49).

Ante la falta de control de estos males emergentes y reemergentes, la Organización Mundial de la
Salud (OMS) introduce un nuevo concepto, el de Enfermedades Tropicales Desatendidas (ETD) (10), las cuales se definen como "un grupo de enfermedades parasitarias y bacterianas que causan enfermedades sustanciales en más de mil millones de personas en el mundo, que afectan a las personas más pobres del mundo, con defectos del tubo neural, perjudicando el desarrollo físico y cognitivo lo que contribuyen en la enfermedad y la muerte de madres y niños, y limitan la productividad en el lugar de trabajo..." $(11,12)$.

Lo más preocupante es que cada año mueren más de 14 millones de individuos a causa de males infecciosos y parasitarios, tales como el cólera y otras afecciones diarreicas epidémicas, dengue severo, dracunculosis (gusano de Guinea), enfermedad de Chagas, esquistosomiasis, filariasis linfática, helmintiasis transmitida por el suelo (ascariasis, anquilostomiasis), leishmaniasis, lepra, oncocercosis, tracoma, tripanosomiasis africana humana (enfermedad del sueño) y úlcera de Buruli, muchos de estos males están relacionados con la desnutrición, la falta de acceso a atención médica y la falta de salubridad $(11,12)$.

Se estima que cada tres segundos muere un niño pobre, en la gran mayoría de los casos por una enfermedad infecciosa, siendo la infección respiratoria aguda la principal responsable de esas numerosas defunciones, especialmente la neumonía; el $99 \%$ de esas defunciones se produce en los países

\footnotetext{
1 Departamento de Enfermedades Infecciosas Tropicales y Dermatológicas, Hospital Nacional Cayetano Heredia, Lima, Perú.

2 Universidad Peruana Cayetano Heredia. Lima, Perú.

a Medico Asistente; Especialista en Enfermedades Infecciosas y Tropicales y Dermatología;

b Vicerrector de Investigación
} 
subdesarrollados (13). Asimismo, las enfermedades diarreicas provocan cada año, la muerte en promedio de casi dos millones de niños menores de cinco años.

Se estima que aproximadamente dos mil millones de personas presentan una infección tuberculosa latente. Se sabe que la tuberculosis produce más muertes de adolescentes y de adultos que cualquier otra enfermedad infecciosa. El paludismo produce la muerte de más de un millón de personas al año, la mayoría de ellas niños, especialmente se producen en el África sub-sahariana, en donde el paludismo provoca una de cada cinco defunciones en niños. El sarampión es la enfermedad más contagiosa de la especie humana, es una importante causa de mortalidad infantil en los países subdesarrollados, provocando unas 900000 defunciones al año (14).

A continuación desarrollaré lo relacionado al nuevo virus Chikungunya, que está causando en América serios problemas de Salud Pública.

\section{VIRUS CHIKUNGUNYA}

El virus del chikungunya (CHIKV) es un virus RNA de la familia Togaviridae, género alfavirus, está relacionado con otros virus similares como el de la encefalitis equina venezolana, Sindbis y del Río Ross. El virus se puede encontrar en reservorios en una serie de especies animales salvajes, así como en ciertas especies de monos y primates y en hombres infectados (15).

\section{Epidemiologia}

El nombre de Chikungunya proviene del idioma makonde que significa enfermedad del hombre retorcido o encorvado, debido al fuerte dolor articular y el encorvamiento provocado por la artritis que caracteriza la enfermedad, por ello recibe otro nombre como artritis epidémica chikungunya. Este virus fue identificado en sudeste Tanzania en 1953, y descrito por primera vez por Robinson Marion, en 1955, es endémico de África y oriundo del África Subsahariana, donde se mantiene un ciclo selvático entre mosquitos (15).

El virus se transmite de manera similar a la fiebre del dengue, el CHIKV apareció en Tanzania, luego poco a poco fue paulatinamente expandiéndose a otras partes del mundo, así desde el año 2004 el CHIKV se ha extendido, provocando epidemias sostenidas de magnitud sin precedentes en Asia y África $(16,17)$.
Si bien algunas zonas de Asia y África se consideran endémicas para esta enfermedad, el virus produjo brotes en muchos territorios nuevos de las islas ubicadas en el Océano Índico y en Italia, por ello el 2011 se alertó su probable entrada en América Latina (17), la cual se produjo en diciembre del 2013 y la Agencia de Salud Pública del Caribe confirmó 10 casos de infectados por el virus chikungunya, causante de una enfermedad similar al dengue, en la isla de San Martín a unos 240 kilómetros al este de Puerto Rico, dándose la alerta a la Organización Mundial de la Salud. Luego se extendió a otras islas del Caribe como Martinica, San Bartolomé, Saint Barthelemy y Guadalupe; según la OPS regional, esta detección de casos locales en estas islas fue la primera vez, luego se produjo en Haití, República Dominicana, Venezuela, Brasil y Colombia; las epidemias de CHIKV han mostrado históricamente una presentación cíclica, con períodos inter epidémicos que oscilan entre los 4 y 30 años $(17,18)$.

En relación al virus chikungunya, la Directora de la OPS/OMS señaló que se trata de una epidemia que se está dispersando rápidamente por la región de las Américas; los primeros casos surgieron en diciembre del 2013 en el Caribe y desde entonces el virus ha llegado a otros países de la región $(19,20)$. Esta reciente emergencia del CHIKV ha aumentado la preocupación y el interés respecto al impacto de este virus sobre la salud pública mundial. En raras ocasiones pueden ocurrir formas graves de la enfermedad con manifestaciones atípicas; por ello el Perú, siguiendo las recomendaciones de la OPS, el año 2014 ha declarado la alerta sanitaria nacional $(18,21)$; a fin de estar preparado los próximos meses y años ante la aparición casos nuevos de CHIKV. Hasta diciembre de 2014 se han reportado en el Perú, 11 casos no nativos de pacientes con este virus procedentes de Republica Dominicana, Haiti, etc. (22).

\section{Clínica}

Luego de la picadura del Aedes aegypti infectado con CHIKV, la mayoría de los individuos presentarán síntomas tras un período de incubación de 3 a 7 días (rango 1-12 días), no todos los individuos infectados desarrollarán síntomas. Estudios serológicos indican que entre el $3 \%$ y el $28 \%$ de las personas con anticuerpos para el CHIKV tienen infecciones asintomáticas.

Los individuos con infección aguda por CHIKV con manifestaciones clínicas o asintomáticos, pueden contribuir a la diseminación de la enfermedad si los 
vectores que trasmiten el virus están presentes y activos en la misma zona. Los adultos mayores son más propensos a experimentar enfermedad atípica grave y muerte (20), aunque no está claro porque los adultos mayores tienen más riesgo de enfermedad grave, puede deberse a que presentan con mayor frecuencia enfermedades concomitantes subyacentes o repuesta inmunológica disminuida. Se han descrito tres cuadros clínicos: aguda, subaguda y crónica $(18,19,20)$.

La infección aguda se presenta como un proceso infeccioso general con fiebre, cefalea, mialgias, nauseas, vómitos, poliartralgias de grandes articulaciones, poliartritis, dolor de espalda, rash maculo-papular, conjuntivitis, etc, los cual duran usualmente 10 días. En relación al compromiso articular, los tobillos, muñecas y las manos son las más afectadas, en ocasiones afectan las articulaciones de la columna vertebral, rodillas y hombros (17).

La forma subguda es la recurrencia de los síntomas luego del episodio agudo, las molestias persisten por dos a tres meses con exacerbación del dolor, tenosinovitis hipertrófica subaguda, y la forma crónica, pasado los tres meses, el paciente persiste con artralgia inflamatoria en muchas articulaciones, se puede presentar artropatía destructiva, fatiga y depresión. Las molestias pueden durar meses y en forma excepcional más de un año $(18,20)$.

El diagnóstico diferencial en la fase aguda incluye especialmente al dengue y a la leptospirosis, artritis pos infecciosa (fiebre Malta, gonococo diseminado), artritis reumatoide juvenil, entre otras.

Se señala que, en la India la proporción de pacientes con síntomas hasta 10 meses después de iniciada la enfermedad llegó a 49\%; de la misma manera ocurrió en Sudáfrica donde $12-18 \%$ de los afectados mantuvieron síntomas 18 meses después del inicio de la enfermedad y en la Isla Reunión, el índice de casos con formas crónicas alcanzó a $80-93 \%$ con síntomas a los 3 meses, $57 \%$ a los 15 y $47 \%$ a los 2 años $(16,17,18,20)$.

Entre estas manifestaciones atípicas se hallan las neurológicas: meningoencefalitis, encefalopatía, síndrome cerebeloso, parestesias, neuropatía y parálisis; oculares: neuritis óptica, iridociclitis, episcleritis, retinitis y uveítis; cardiovasculares: miocarditis, pericarditis, falla cardiaca, arritmias e inestabilidad hemodinámica; dermatológicas: hiperpigmentación fotosensible, intertrigo y dermatosis vesicular; renales: nefritis e insuficiencia renal aguda; respiratorias: neumonía e insuficiencia respiratoria; y otras manifestaciones: hepatitis, pancreatitis e hipoadrenalismo.

Si bien la recuperación es lo usual, el periodo de convalecencia puede ser prolongado (en ocasiones hasta un año o más). El dolor articular persistente puede requerir tratamiento analgésico, incluyendo terapia antiinflamatoria prolongada. Se cree que una vez expuesto al CHIKV los individuos desarrollan inmunidad prolongada que los protege contra la reinfección. No existe un tratamiento farmacológico antiviral específico para la CHIK. No hay evidencia de que el virus se transmita a través de la leche materna.

Se consideran que las muertes relacionadas con infección por CHIKV son raras. Sin embargo, se reportó un aumento en las tasas brutas de mortalidad durante las epidemias de 2004-2008 en la India y Mauricio.

\section{Diagnóstico}

Durante la primera semana del inicio de los síntomas deben analizarse por métodos serológicos (ELISA para la detección de IgM e IgG) y virológicos (RT-PCR y aislamiento del virus. Las muestras generalmente son sangre o suero, pero en casos neurológicos con características de meningoencefalitis también se puede obtener líquido cefalorraquídeo (LCR) $(17,18,20)$.

No se ha descrito hallazgos hematológicos patognomónicos en las infecciones por CHIKV. Los hallazgos de laboratorio anormales pueden incluir ligera trombocitopenia $\left(>100000 / \mathrm{mm}^{3}\right)$, leucopenia y linfopenia, y enzimas hepáticas elevadas. Puede presentarse hipocalcemia. La velocidad de sedimentación globular está generalmente elevada. La proteína $\mathrm{C}$ reactiva aumenta durante la fase aguda y puede permanecer elevada por algunas semanas $(17,18,20)$.

\section{Terapia}

El manejo es sintomático, dado que no existen drogas antivirales. Luego de excluir enfermedades más graves como malaria, dengue e infecciones bacterianas, se le trata con terapia sintomática y de soporte; es decir, reposo y fisioterapia. Usualmente se usa acetaminofén o paracetamol para el alivio de la fiebre, ibuprofeno, naproxeno o algún otro agente antiinflamatorio no esteroideo (AINE) para aliviar el 
componente artrítico de la enfermedad. En algunos casos severos de daño articular se ha empleado metrotexate, cloroquina o corticoides $(17,20)$.

\section{Prevención y control}

Dado que el virus CHIKV y el dengue compartan el mismo vector, las medidas de prevención y control son las mismas que se emplean para el control del dengue $(17,18,20,21,23,24)$ :

1) Búsqueda y eliminación del Aedes aegypti, que además incluye tratamiento o eliminación de los criaderos.

2) Eliminar los huevos de los envases secos que han contenido agua y que se encuentran sin tapa, ya que el embrión dentro del huevo es capaz de resistir largos períodos de desecación (meses o hasta por más de 1 año), al volver a tener contacto con el agua la eclosión se da en tan sólo alrededor de 15 minutos.

3) Lavar diariamente los bebedores de los animales.

4) Los pobladores deben identificar los probables depósitos que podrían ser "criaderos" del mosquito, por ejemplo: tanques, botellas, latas, floreros, ollas, entre otros, ya que en estos recipientes se queda el agua, donde se podrán depositar los huevos del Aedes aegypti.

5) De no poder ser eliminados los recipientes en los techos de las casas, se deberá colocar "boca abajo", y los cilindros y tanques de agua tienen que ser tapados. En el caso de los floreros deberán usar arena húmeda.

6) La nebulización de insecticidas en ULV (volumen ultra reducido): Piretroides, preferentemente en base acuosa, AquaReslin $\AA$, Super y Solfac ${ }^{\circledR}$ EW 050 (permetrina 10,87\%, esbioletrina $0,51 \%$ y butóxido de piperonilo $11,07 \%$ o ciflutrina $5 \%$ ); estos insecticidas no son tóxicos para los humanos.

7) Para evitar criaderos del mosquito del dengue: Eliminar todo objeto que ya no se use y pueda acumular agua, mantener limpios el techo y patios de la vivienda.

8) Los directivos de las regiones, de las municipalidades, obliguen a las personas a usar floreros sin agua o usar arena húmeda en los cementerios.

9) Utilizar mallas, mosquiteros en ventanas y puertas para disminuir el contacto con el insecto.

10)Las medidas para evitar las picaduras de mosquitos consisten en: Usar ropa que cubra la máxima superficie posible de piel, aplicar repelente de mosquitos en la piel expuesta y en la ropa, siguiendo sus instrucciones de uso, utilizar mosquiteros para proteger a los niños, ancianos y enfermos, o cualquier otra persona que repose durante el día.

\section{Correspondencia}

Ciro Maguiña Vargas

Correo electrónico: ciro.maguina@upch.pe

\section{REFERENCIAS BIBLIOGRÁFICAS}

1. Lederberg J, Shope R, Oaks S Jr.(Editores). Microbial threats to health in the United States. Washington DC: Institute of Medicine, National Academy Press; 1992.

2. Gotuzzo E. Enfermedades emergentes y reemergentes en el Perú. Rev Med Hered. 2002; 13(2): 37-39.

3. Maguiña C. La nueva influenza A/H1N1. Acta Médica Peruana. 2009; 26(2):72-73.

4. Organización Panamericana de la Salud. La situación del cólera en las Américas. Boletín epidemiológico. 1991; 12(1):1-24.

5. Centers for Disease Control and Prevention. Cholerae in Perú. MHWR.1991; 40(6):199-202.

6. Maguiña C, Seas C, Galán E, Santana J. Historia del cólera en el Perú en 1991. Acta Med Per. 2010; 27(3): $212-217$.

7. Maguiña C. Consideraciones sobre el dengue (Editorial). Diagnóstico (Perú). 2002; 41(4):1.

8. Organización Panamericana de la Salud. Resurgimiento del dengue en las Américas. Boletín Epidemiológico.1997; 18 (2): 1-6.

9. Cruz A, Rolland-Burger L. El virus del dengue. Diagnostico. 2002; 41(4): 165-172.

10. World Health Organization. Enfermedades tropicales desatendidas: notas descriptivas. Geneva: World Health Organization; 2012 (Citado el 7 de diciembre del 2014). Disponible en: http://www.who.int/topics/ tropical_diseases/factsheets/neglected/es/

11. Cabezas C. Enfermedades infecciosas desatendidas: un permanente reto para la salud pública y la equidad en el Perú. Rev Peru Med Exp Salud Publica. 2014; 31(2):326-335.

12. Centers for Disease Control and Prevention. Neglected tropical diseases. Atlanta: CDC; (Citado el 7 de diciembre del 2014). Disponible en: http://www. cdc.gov/globalhealth/ntd/

13. Sánchez N. Infecciones Respiratorias Agudas. Reporte técnico de Vigilancia. 1996;1(1). (Citado el 7 de diciembre de 2014). Disponible en: http://www. bvs.sld.cu/uats/rtv_files/rtv0196.html

14. Centers for Disease Control and Prevention of diseases. ¿Qué pasaría si suspendiéramos las campañas de vacunación?.Atlanta: Centers for Disease Control and Prevention of diseases; 2011. 
(Citado el 7 de diciembre de 2014). Disponible en: http://www.cdc.gov/spanish/inmunizacion/ importancia.html

15. Sourisseau M, Schilte C, Casartelli N, et al. Characterization of reemerging chikungunya virus. PLoS Pathog. 2007; 3(6): e89.

16. Powers AM, Logue $\mathrm{CH}$. Changing patterns of chikungunya virus: re-emergence of a zoonotic arbovirus. J Gen Virol. 2007; 88 (9): 2363-77.

17. Organización Panamericana de la Salud/Organización Mundial de la Salud/ Centros para la Prevención y Control de Enfermedades. Preparación y respuesta ante la eventual introducción del virus chikungunya en las Américas. Washington D. C.: Centros para la Prevención y Control de Enfermedades (CDC) y Organización Panamericana de la Salud; 2011. (Citado el 7 de diciembre del 2014). Disponible en: http://www.paho.org/hq/index.php?option=com_con tint\&view $=$ article \&id=9053\&Itemid=39843\&lang= es

18. Dirección de Salud IV Lima Este, Ministerio de Salud. Alerta Epidemiologica Nacional. Lima, Perú: Ministerio de Salud; 2014. (Citado el 7 de diciembre del 2014). Disponible en: http://www.limaeste.gob. pe / 1 i m a e s t e / D I R E C C I O N E S / O E P / VigilanciaEpidemio/SemanasEpi/Alertas\%20 Epidemiol\%C3\%B3gicas/A\%C3\%B10\%202014/ Alerta\%20Epid.Chikungunya\%202014.pdf

19. Fischer M, Staples JE; Arboviral Diseases Branch, National Center for Emerging and Zoonotic Infectious Diseases; CDC. Notes from the field: Chikungunya virus spreads in the Americas - Caribbean and South America, 2013-2014. MMWR. 2014; 63 (22): 500501.

20. Placeres JF, Martínez J, Chávez L, Rodríguez E, de León L. Fiebre causada por el virus Chikungunya, enfermedad emergente que demanda prevención y control. Rev. Med. Electrón. [revista en la Internet]. 2014 Oct [citado 07 de diciembre de 2014]; 36(5): 596-609. Disponible en: http://scielo. sld.cu/scielo.php?script $=$ sci_arttext\&pid $=$ S1684$18242014000500007 \& \operatorname{lng}=$ es.

21. Ministerio de Salud. Plan Nacional de Preparación y Respuesta frente a la Fiebre de Chikungunya - Perú, 2014. Resolución Ministerial N ${ }^{\circ} 427$ - 2014/MINSA. Lima, Perú: Ministerio de Salud; 2014.

22. Ministerio de Salud. En el Perú no hay casos autóctonos de chikungunya. Lima: Ministerio de Salud;2014. (Citado el 7 de enero del 2015). Disponible en: http://www.minsa.gob.pe/?op=51\&nota $=15912$

23. Organización Panamericana de la Salud. Alerta epidemiológica. Fiebre por chikungunya. Washington DC: Organización Panamericana de la Salud; 2013. (Citado el 9 de diciembre de 2013. Disponible en: http://www.paho.org/hq/index.php?option=com docman\&task=doc_view\&gid=23807+\&Itemid=999 999\&lang=es

24. Panamerican Health Organization. Cummulative number of reported cases of Chikungunya Fever in the Americas, by Country or Territory, 2014. Washington DC: Panamerican Health Organization; 9 may 2014. 